\title{
El impacto de los movimientos sociales en la legislación sobre vivienda*
}

\author{
Elisa Moreu Carbonell \\ Profesora Titular de Derecho Administrativo \\ Universidad de Zaragoza
}

\begin{abstract}
SUMARIO: I. INTRODUCGIÓN. II. EL SALTO DESDE EL ACTIVISMO SOGIAL HACIA LOJURÍDICO. III. ACTIVISMO NORMATIVO: LAS REFORMAS MÁS MEDIÁTICAS. 1. ¡Abajo la especulación! Caza y captura de viviendas vacías. 2. ¡Exprópiense!. 3. Esto nos pasa por vivir por encima de nuestras posibilidades. IV. OBSTÁCULOS DE ESTA CASCADA NORMATIVA EN MATERIA DE VIVIENDA. 1. Se está avanzando a pasos de gigante, pero sigue siendo insuficiente la protección jurisdiccional del derecho a la vivienda. 2. El confuso diseño competencial y el reforzamiento del poder central vía extensión competencial. 3. Fragmentación excesiva de las políticas de vivienda. V. EN CONCLUSIÓN. BIBLIOGRAFÍA CITADA.
\end{abstract}

RESUMEN: Este estudio versa sobre el impacto jurídico de los movimientos sociales que demandan una intervención pública más intensa en el derecho a la vivienda. En efecto, el activismo social está resquebrajando el modelo de participación ciudadana en los procesos legislativos e incluso alterando sustancialmente el contenido y la finalidad de la legislación española sobre vivienda. Mi trabajo es, por tanto, una reflexión sobre las consecuencias de los movimientos sociales en los principios de calidad normativa y buena regulación en la vivienda.

PALABRAS-CLAVE: Derecho a la vivienda. Activismo social. Participación ciudadana. Calidad de las normas. Buena regulación.

ABSTRACT: This study deals with the legal impact of social movements that demand more intense public intervention on housing right. Indeed, social activism

*Este trabajo se enmarca en el Proyecto de Investigación "ANACOBE: Análisis de costes y beneficios en el Derecho Público: métodos e instrumentos para la mejora de la regulación" ( DER2012-31112) dirigido por la prof. Dra. Dolors CANALS AmetLleR y nace de la conferencia impartida en la jornada Reflexiones sobre la mejora de las normas y la posición de la ley en los sistemas jurídicos actuales que se celebró en la Universidad de Girona el 20 de mayo 2016. Supone la actualización y puesta al día de mi contribución al libro-homenaje a Manuel Ballbé Prunes, dirigido por J. Gifreu Font, M. Bassols Coma y A. Menéndez Rexach (2016). 
is cracking the framework for citizen participation in the legislative process and even substantially altering the content and the purpose of the Spanish housing regulation. My research is, therefore, a contribution to the consequences of social movements in the principles of good regulation and quality intervention in the field of housing law.

KEY WORDS: Housing Law. Social activism. Citizen participation. High-quality regulation. Better regulation.

\section{INTRODUCGIÓN}

El derecho a la vivienda constituye un excelente campo de pruebas, uno de esos ámbitos de referencia que sirven de modelo y ejemplo para la construcción del sistema de Derecho administrativo, en el sentido que Schmidt-Assmann (2003) da a esta expresión. Como apunta GonzÁlez Ordovás (2009, 49), la vivienda es un "ejemplo incuestionado de la lucha por el Derecho" y un "derecho social en obras". Desde 2008, el estallido de la burbuja inmobiliaria nos ofrece datos terribles sobre el impacto que está teniendo en nuestro país la crisis económica, datos por todos conocidos o, al menos intuidos ${ }^{1}$. Sin embargo, ¡oh sorpresa!, nuestro país está muy por debajo de la media europea en financiación de las políticas sociales. De modo que, como afirma Vaquer Caballería (2014, 34), "la politica de vivienda es la peor financiada de entre nuestras políticas sociales en comparación con los países europeos" y hemos llegado realmente a un punto crítico (Ponce Solé, 2015).

En épocas de crecimiento y desarrollo económico, la vivienda se ha contemplado siempre desde una vertiente patrimonial, como bien de inversión (TeJEDor Bielsa, 2012, 59), aunque no sea ese el contenido del artículo 47 de la Constitución (Vaquer Caballería, 2015: 126). La crisis económica ha modificado la percepción que los ciudadanos tienen del derecho a la vivienda, más cercana a la que subyace en el texto constitucional, como bien esencial para el desarrollo de la vida en sociedad, para la emancipación de los ciudadanos y la formación de los hogares. Si la percepción del derecho a la vivienda ha avanzado en este período de crisis económica, es lógico que el Derecho idee nuevas fórmulas de intervención acordes con dicha evolución.

Según Amnistía Internacional (2015), desde que comenzó la crisis económica en España, cientos de miles de personas han perdido su casa o corren peligro de perderla en ejecuciones hipotecarias. En concreto, el Consejo General del Poder Judicial (2013) calcula que más del 89\% de lanzamientos derivados de ejecuciones hipotecarias realizados en España corresponden a hipotecas concedidas a familias sobre su vivienda habitual. Por otro lado, en España son muy elevados tanto el número de viviendas vacías (es muy significativo que el 30\% de las viviendas deshabitadas de Europa se encuentren en nuestro país) como el de personas sin hogar (según informes de la ONU (2008) y del Defensor del Pueblo (2012), en España hay entre 30.000 y 50.000 personas sin techo). 
No voy a hacer aquí un análisis detallado de todas las reformas normativas que se producen a toda velocidad en el ámbito de la vivienda. La perspectiva que quiero adoptar es otra: el impacto de todos los movimientos sociales que demandan mayor intervención pública en la vivienda que, con su activismo, están resquebrajando no sólo el modelo de participación ciudadana en los procesos legislativos, sino el sistema mismo de fuentes legislativas. Mi trabajo pretende ser, por tanto, una reflexión sobre las consecuencias de este activismo social en la calidad normativa y la buena regulación. Como advierten Montoro Chiner y Sommermann (2015), las exigencias de una buena legislación aumentan con la complejidad creciente de las sociedades modernas y la aceleración de los procesos económicos, particularmente en tiempos de crisis; así que me ha parecido oportuno ofrecer estas reflexiones a propósito de las reformas en el sector de la vivienda.

\section{EL SALTO DESDE EL ACTIVISMO SOCIAL HACIA LOJURÍDICO}

Los movimientos sociales y las plataformas ciudadanas por el derecho a una vivienda digna surgen a mediados de la primera década del siglo XXI, impulsados por el estallido de la burbuja inmobiliaria y en un marco de crisis económica ${ }^{2}$. Se trata de movimientos muy heterogéneos que tienen el común el poder encauzar las reclamaciones de ciudadanos afectados por la crisis inmobiliaria, con problemas para pagar la hipoteca, incursos en procesos de ejecución hipotecaria o desahuciados, víctimas de malas prácticas bancarias, y, en general, ciudadanos con dificultades económicas que se traducen en problemas de acceso a una vivienda digna. ${ }^{3}$

Quizás lo propio de estos movimientos ciudadanos del siglo XXI sea la repercusión y la amplificación de sus acciones a través del uso de las tecnologías de la información y la comunicación, TICs, y de las redes sociales (Haro Barba y Sampedro Blanco, 2011: 160). La doctrina (desde las disciplinas económicas, la sociología y la ciencia política) empieza a hablar ya de un fenómeno de "innovación social" que parte de la constatación de que muchas necesidades, demandas y expectativas de los ciu-

2 Evidentemente, los movimientos sociales no son propios del presente siglo, pues el concepto de "movimiento social" fue incorporado al vocabulario académico a medidados del siglo XIX por influjo de la obra de Lorenz von Stein y son el fruto natural de las crisis económicas y sociales (he manejado la versión española de E. Tierno Galván publicada en 1957). De hecho, el movimiento okupa de los años 70 y 80 del siglo XX es un claro antecedente de los "modernos" movimientos sociales antidesahucios.

3 Nacen como movimientos sociales apolíticos y de funcionamiento asambleario, aunque alguno de ellos han terminado diluyéndose en partidos políticos y participando en procesos electorales, sobre todo en el ámbito municipal. Cronológicamente, parece que la primera organización fue la Plataforma por una Vivienda Digna, que se crea en 2003, y luego han surgido otros como la Plataforma de afectados por la hipoteca (2009) o STOP desahucios (2011). A las reivindicaciones sociales por una vivienda digna se suman también sindicatos, asociaciones de vecinos, asociaciones de consumidores (como ADICAE) y otros colectivos. 
dadanos no se abordan eficazmente por parte de los poderes públicos, en un contexto de gradual desafección ciudadana y déficit de legitimidad del sistema democrático (Conejero Paz y Redondo Lebrero, 2016, 2). Este nuevo enfoque de la transformación social ahonda en la necesidad de buscar soluciones innovadoras capaces de resolver necesidades sociales concretas, cambios institucionales en programas, legislaciones y, en definitiva, cambios en la forma de ejercer la acción de gobierno.

Pues bien, el salto desde el activismo social hacia el Derecho es siempre complicado. Es cierto que el Derecho es un instrumento de cambio social, que no se limita a ordenar la realidad existente y que puede transformar los hábitos de los ciudadanos. Pero este salto hacia la regulación jurídica encuentra obstáculos como la lentitud de los procesos normativos, su escasa permeabilidad para adaptarse a los cambios o el formalismo, junto con la ortodoxia doctrinal, su resistencia al cambio o el sesgo del statu quo (Doménech Pascual, 2016, 5). Por eso, es natural que surjan fricciones en cuanto a los roles que han de desempeñar los actores político-administrativos y la ciudadanía en la conformación de las políticas públicas y como fuentes de producción normativa (Conejero Paz y Redondo Lebrero, 2016, 9).

En el sector de la vivienda, la presión social encuentra válvulas de escape en todos los ámbitos del poder: en el poder legislativo, a través de reformas legislativas que están empezando a cambiar la tradicional regulación del artículo 47 de la Constitución; en el poder ejecutivo, con un enérgico activismo político-administrativo que tiene como protagonistas a los Ayuntamientos españoles; y en el poder judicial, donde un grupo de jueces concienciados está encauzando también algunas demandas de los ciudadanos. Del activismo normativo me ocupo con más detalle en el epígrafe siguiente; unas pequeñas líneas para exponer a grandes rasgos las otras modalidades de activismo social.

Denomino "activismo político-administrativo" a la acción decidida de algunas instituciones públicas españolas, Ayuntamientos especialmente, para llevar a la práctica políticas de defensa del derecho a la vivienda. El nivel territorial local ha sido un buen campo de pruebas para ensayar instrumentos jurídicos nuevos en este ámbito: Ayuntamientos que se niegan a colaborar en los procedimientos de ejecución hipotecaria practicados en su término municipal, que median entre las partes, que actúan para reducir el parque de pisos vacíos, que promueven medidas económicas y de fomento. ${ }^{4}$ ¿Cuál es la razón de este cambio de actitud? 
Tras las elecciones municipales de mayo de 2015, una serie de candidaturas de "confluencia ciudadana" alcanzaron puestos políticos. Con el antecedente del movimiento $15 \mathrm{M}$, la ciudadanía empezó a organizarse para acceder al poder municipal, así que los protagonistas fueron ciudadanos (afiliados a partidos políticos o no, activistas sociales y locales, personas sin adscripción) que pusieron en marcha proyectos de construcción de instrumentos de participación política, pero con los partidos políticos en segundo plano. Lo innovador de estos movimientos de participación política es que surgen como espacios de confluencia entre el activismo social y local y el activismo político (Marcellesi y Martínez Rodríguez, 2015). Otras instituciones, como el Defensor del Pueblo o sus equivalentes autonómicos (el defensor del pueblo andaluz o el ararteko vasco), han manifestado en sus informes una honda preocupación por la garantía efectiva del derecho a la vivienda, encauzando las quejas ciudadanas (por ejemplo, en su informe de 2012). Aunque el papel de estos informes es meramente testimonial y pocas veces conducen a un reconocimiento efectivo de los derechos, llama la atención que se defiendan medidas concretas y extraordinarias de actuación tales como arrendamientos forzosos para que los deudores de buena fe puedan mantener sus viviendas o locales de negocio.

En segundo lugar, el derecho a la vivienda está abriéndose paso como derecho subjetivo gracias al "activismo judicial" de un sector de la judicatura que, sin ser abrumador comienza a ser visible. Atienza (2013a 117 y 123) lamenta incluso que los jueces no hayan comenzado a comportarse antes como "algo distinto a cobradores del frac" y acusa su inacción a una "concepción formalista del Derecho" que se desentiende de las consecuencias de sus decisiones. No se trata de reivindicar a los jueces estrella ni tampoco de que los jueces actúen como legisladores (este matiz peyorativo se observa en García Inda, 2015: 7) ${ }^{5}$. Estamos, simplemente, ante jueces activos que reclaman la complejidad de la tarea de aplicar e interpretar la norma y luchan contra el abuso del derecho. El juez independiente, responsable y, por tanto, imparcial no es un ser enclaustrado en un compartimento estanco al entorno social, no es sinónimo de un juez impli-

que citan Moltó y Ponce (2016) y Escudé (2017). El Ayuntamiento de Terrassa ha iniciado una política de movilización de pisos vacíos, requiriendo a diversas entidades bancarias propietarias para que procedan a su inmediata ocupación y advirtiéndoles de que, en caso contrario, se abrirá expediente sancionador con fundamento en la Ley 18/2007, de derecho a la vivienda de Cataluña. Al respecto, ya hay sentencias favorables al Ayuntamiento que desestiman la solicitud de suspensión cautelar instada por la entidad financiera y rechazan que constituya una actuación constitutiva de vía de hecho (sentencia n ${ }^{\circ}$ 192/2015 del Juzgado de lo Contencioso-Administrativo 10 de Barcelona, de 15 julio 2015 y otras en http://www.ac-lg.com/ca/ noticies/.

García Inda $(2015,7)$ cita, en concreto, un índice de libertad económica de España (2015) en el que los tribunales han fallado en contra de los principios básicos de la economía de mercado. 
cado activamente en el devenir del contexto que le rodea (Carrillo, 2015: 17). El derecho a la vivienda es un caso paradigmático de activismo judicial desde hace más de medio siglo, cuando unos “audaces” jueces americanos (Ponce Solé, 1999) asumieron que el ejercicio de los derechos sociales está condicionado por la acción u omisión de los poderes públicos y que el poder judicial puede contribuir a paliar sus deficiencias (Rodríguez Arana, 2015). El debate surge con fuerza en los países del centro y sur del continente americano y esta variedad de activismo se califica ya como una "tendencia incipiente neoconstitucionalista en Latinoamérica y otras regiones del sur global", con intervenciones ambiciosas en litigios relativos a derechos sociales como la vivienda o la salud (al respecto, RodríGuez GARAviTO, Rodríguez Franco, 2015).

Volviendo a nuestro país, son muy conocidas las decisiones de algunos juzgados y tribunales que han recurrido a la dación en pago como instrumento para paliar los efectos de la crisis económica en el ámbito de la vivienda. ${ }^{6}$ Esta figura estaba algo "adormecida" en nuestro ordenamiento y ahora cobra especial protagonismo como mecanismo para sortear las dificultades de la crisis económica (Garcías de España, 2013: 4). Tuvo igualmente una enorme repercusión mediática la sentencia del TJUE de 14 marzo de 2013, Mohamed Aziz c. Catalunyacaixa (ECLI: EU:G:2013:164) que se sitúa en el origen de las reformas legislativas sobre cláusulas abusivas en nuestro país. Atienza (2013b: 16) destaca que esta sentencia contribuyó a avivar el movimiento anti-desahucios en España, generó la necesidad de llevar a cabo un cambio legislativo y provocó un cambio de actitud en los jueces que han dejado de comportarse como "cobradores del frac" y han empezado a sacar partido del remedio que el propio sistema habilita para paliar situaciones en las que la aplicación estricta del Derecho lleva a consecuencias manifiestamente injustas, que es la institución del abuso del derecho del artículo 7.2 del Código Civil.

\footnotetext{
A partir del Auto de la Audiencia Provincial de Navarra, de fecha 17 de diciembre de 2010 (ECLI:ES:APNA:2010:1A), surge una novedosa corriente jurisprudencial en torno a la dación en pago, que fue posteriormente avalada por otras Audiencias Provinciales como la de Gerona (Auto de 16 septiembre 2011, ECLI:ES:APGI:2011:671A), si bien es cierto que con el voto particular de uno de sus magistrados.
} 


\section{ACTIVISMO NORMATIVO: LAS REFORMAS MÁS MEDIÁTICAS}

En los últimos años, tanto el Estado ${ }^{7}$ como las comunidades autónomas ${ }^{8}$ confluyen en sus reformas relativas a la vivienda, en un activismo normativo que experimenta con nuevos instrumentos y técnicas para garantizar el acceso a la vivienda y evitar situaciones de vulnerabilidad social: auxilio de deudores hipotecarios, daciones en pago, protección contra cláusulas abusivas, leyes antidesahucios, intervención en viviendas vacías, medidas fiscales, programas sociales, etc, un panorama general en PONGE SOLÉ, 2007 y VAQUER, PONCE, ARNAIZ, 2016). Sin embargo, la convivencia de las normas estatales y autonómicas no está siendo pacífica. El gobierno de España considera que las leyes autonómicas alteran el reparto competencial, perturban gravemente sus medidas de política económica y ponen en peligro el funcionamiento de los mercados hipotecarios. Por eso, prácticamente todas las leyes autonómicas de medidas relativas a la vivienda aprobadas desde 2013 han sido impugnadas ante el Tribunal Constitucional. En consecuencia, su vigencia ha quedado suspendida y, a tenor del fallo estimatorio del recurso interpuesto contra la ley andaluza (el único resuelto hasta la fecha, STC 93/2015, de 14 de mayo), cabe intuir que todas llevan el mismo camino. Parece que los legisladores autonómicos legislan conscientemente de que sus normas son -o van a ser declaradas- inconstitucionales.

El gobierno de España puso en marcha políticas de acción dirigidas a mejorar la situación de las personas en riesgo de perder su vivienda y aliviar la situación de los deudores hipotecarios. Adoptó al efecto el Real Decreto-Ley 27/2012, de 15 de noviembre, que luego se convirtió en Ley 1/2013, de 14 de mayo, de medidas para reforzar la protección a los deudores hipotecarios, reestructuración de la deuda y alquiler social, modificada parcialmente por Real Decreto-ley 1/2015, de 27 de febrero y por Real Decreto-ley 5/2017, de 17 de marzo. Una de las medidas aprobadas fue la suspensión del lanzamiento en procesos de ejecución hipotecaria por un plazo de cuatro años - que se amplió posteriormente a siete- desde la entrada en vigor de la Ley (es decir, desde el 15 de mayo de 2013, plazo que termina el 15 de mayo de 2020), para aquellos deudores que fueran a perder su vivienda habitual y se encontraran en supuestos de especial vulnerabilidad económica. Además, contempla la creación de un fondo social de viviendas propiedad de las entidades de crédito para ofrecer cobertura a los desalojados de su vivienda habitual por el impago de un préstamo hipotecario, siempre que concurran las circunstancias de especial vulnerabilidad previstas en la norma. Por otro lado, el R. Decreto-Ley 1/2015, de 27 de febrero, introdujo un "mecanismo de segunda oportunidad" para facilitar daciones en pago selectivas, permitiendo que quien haya perdido todo por haber liquidado la totalidad de su patrimonio en beneficio de sus acreedores pueda verse liberado de la mayoría de las deudas pendientes tras la liquidación.

8 He seleccionado especialmente las leyes de vivienda de Cataluña, Andalucía, Navarra, Canarias, País Vasco y Valencia, porque todas contemplan medidas drásticas para paliar situaciones excepcionales de emergencia social. Aunque popularmente se conocen como "leyes antidesahucios", en realidad su objetivo va más lejos, y comparten una mayor sensibilidad ante las dificultades de acceso a la vivienda en estos momentos de crisis que conduce a una redefinición de su función social. 


\section{1. ¡Abajo la especulación! Gaza y captura de viviendas vacías}

La vivienda vacía o deshabitada sin causa justificada durante un período de tiempo está empezando a definirse como un incumplimiento de la función social de la propiedad, al que se asocian consecuencias distintas para sus propietarios, tales como medidas sancionadoras, fiscales o incluso expropiatorias. Entre otros objetivos, se plantea la reduccción del stock de viviendas vacías y aumentar su disposición para el alquiler social.

El control de las viviendas vacías parece ser de tres tipos: por un lado, se regula la obligación de mantener las viviendas ocupadas para cumplir la función social de la propiedad (a), pudiendo establecer sanciones para los propietarios de viviendas deshabitadas (b) y, por otro lado, se grava con determinados impuestos contra viviendas vacías (c).

(a) El legislador estatal no impone inequívocamente el deber de mantener habitadas las viviendas (a salvo el régimen de las viviendas protegidas), a cuyo incumplimiento no asocia ninguna medida de policía ni sancionadora. Pero sí apunta la necesidad de dar destino habitacional a las viviendas desocupadas cuando dispone que son fines de las políticas públicas "posibilitar el uso residencial en viviendas constitutivas de domicilio habitual" y "favorecer y fomentar la dinamización económica y social y la adaptación, la rehabilitación y la ocupación de las viviendas vacías o en desuso" (artículo 3.3 b) de la Ley del suelo y rehabilitación urbana, Texto Refundido aprobado R.D. Legislativo 7/2015, de 30 de octubre). Por su parte, el Preámbulo de la Ley 4/2013, de 4 de junio, de flexibilización y fomento del mercado de alquiler de viviendas, reconoce que existe "un elevado número de viviendas en propiedad, vacías y sin ningún uso" que aconseja la puesta en marcha de medidas para atraerlas al mercado.

Ha sido el legislador autonómico, tras las últimas reformas nacidas de la crisis económica, quien ha consolidado el deber de destinar la vivienda a uso habitacional. La Ley catalana 18/2007 dispone que "existe incumplimiento de la función social de la propiedad de una vivienda o un edificio de viviendas en el supuesto en que la vivienda o el edificio de viviendas estén desocupados de forma permanente e injustificada" (artículo 5.2.b). La ley andaluza 1/2010 enuncia con rotundidad que "forma parte del contenido esencial del derecho de propiedad de la vivienda el deber de destinar de forma efectiva el bien al uso habitacional previsto por el ordenamiento jurídico" (artículo 1.3), inciso este que ha sido declarado inconstitucional por la STC 93/2015 . Por su parte, la Ley Foral Navarra 10/2010 parece limitar este deber únicamente a las personas jurídicas, ya que, a pesar de regular

\footnotetext{
Dicho esto, me parece importante la matización que formula el propio Tribunal Constitucional cuando señala que "esta conclusión no significa que la configuración constitucional del derecho de propiedad impida al legislador restringir de este modo la amplitud de las facultades de uso y disposición del propietario de vivienda, análisis que no procede desarrollar en este momento" (FJ. 13). En definitiva, el Tribunal Constitucional reconoce al legislador au-
} 
un procedimiento administrativo para la declaración de viviendas deshabitadas, "en orden al ejercicio de la potestad sancionadora sólo se considerará vivienda deshabitada aquella cuya titularidad corresponda a una persona jurídica" (artículo 42bis.5), sin que encontremos preceptos equivalentes a los de las leyes catalana o andaluza en relación con la función social de la vivienda. Este precepto se encuentra suspendido mientras se resuelve el recurso de inconstitucionalidad interpuesto por el Presidente del Gobierno. Y en fin, la última reforma operada por Ley 2/2017, de 17 de febrero, de emergencia social de la vivienda de Extremadura, impone la obligación de destinar la vivienda a domicilio habitual y permanente de su titular y regula las consecuencias de la declaración de vivienda desocupada.

(b) El incumplimiento del deber relativo a la efectiva ocupación de la vivienda se tipifica como infracción -normalmente muy grave- y puede desembocar en la correspondiente sanción administrativa. La iniciación del procedimiento sancionador exige la previa declaración administrativa de vivienda deshabitada y, en el caso de la ley catalana, el ofrecimiento de medidas de fomento a sus titulares, pudiendo adoptar, en su caso, las medidas provisionales que se consideren oportunas, tales como la clausura del inmueble o la imposición de multas coercitivas. Las sanciones impuestas oscilan entre los los 9000 euros en la ley andaluza y los 900.000 euros en la ley catalana, pasando por la horquilla de entre 30.001 a 300.000 euros en la ley navarra. Las disposiciones sancionadoras de estas leyes se basan en una serie de presunciones de no habitación, en indicios que hay que acreditar en expediente contradictorio, tales como los datos del padrón de habitantes, los consumos de agua, gas y electricidad, la recepción de correo y otros; precisamente, esta ha sido una de las razones que llevó al Presidente del Gobierno a impugnar la Ley andaluza de 2013 ante el Tribunal Constitucional, al considerar que los criterios para concretar la definición de "vivienda deshabitada" se basan en meros indicios, contraviniendo con ello el principio de presunción de inocencia que rige el procedimiento administrativo sancionador (artículos 24 y 25 de la Constitución).

El deber de ocupación efectiva impuesto a los propietarios de viviendas es un límite inherente a la función social de la propiedad (artículo 33 de la Constitución). Desde una perspectiva competencial, ¿pueden las Comunidades Autónomas modular estos límites? Es evidente que las Comunidades autónomas tienen competencia exclusiva en materia de vivienda (artículo 149.1.8 ${ }^{\circ}$ de la Constitución, recogida en sus respectivos Estatutos de Autonomía) y que el artículo 47 del texto constitucional no constituye por sí mismo un título competencial, sino un mandato o directriz constitucional que ha de informar la actuación de todos los poderes públicos en el

tonómico la posibilidad de delimitar el contenido de la función social de la propiedad... aunque no a través de decreto-leyes. 
ejercicio de sus competencias (STC 152/1988, de 20 julio, FJ. 2). Por tanto, creo que la respuesta a la pregunta anterior debe ser afirmativa a la luz de la jurisprudencia del Tribunal Constitucional, ya desde su STC 37/1987, de 26 de marzo, relativa a la ley de reforma agraria de Andalucía, y que resulta extrapolable al ámbito de la propiedad urbana. En cualquier caso, la exclusividad de las competencias autonómicas tiene un alcance relativo, y así, en materia de vivienda el Estado ostenta una cierta incidencia mediata con fundamento en otros títulos competenciales (ordenación del crédito, planificación de la actividad económica y otros).

En los recursos de inconstitucionalidad resueltos y pendientes ante el Tribunal Constitucional, el Gobierno, avalado por los dictámenes del Consejo de Estado, alega que la ley autonómica no puede regular el contenido esencial del derecho a la propiedad de la vivienda, porque con ello afecta a las condiciones básicas de su ejercicio y vulnera la competencia exclusiva del Estado para fijar las condiciones básicas que garanticen la igualdad de los españoles en ejercicio de sus derechos y deberes constitucionales, así como su competencia en materia de legislación civil (artículo 149.1.1 ${ }^{\circ}$ y $8^{\circ}$ de la Constitución). En definitiva, la delimitación del derecho de propiedad corresponde a la legislación civil, y no en el marco de la competencia sectorial en materia de vivienda.

No estoy de acuerdo con esta conclusión. En mi opinión, las competencias exclusivas de una comunidad autónoma en materias como el urbanismo y la vivienda sí permiten al legislador autonómico imponer al propietario el deber de efectiva ocupación, sin que ello suponga invasión de competencias estatales. El artículo 33 del texto constitucional confirma que la función social de la propiedad "determinará su contenido, de acuerdo con las leyes", y esta remisión legal debe hacerse conforme al reparto competencial fijado en la propia Constitución. En este sentido, el Dictamen $n^{\circ}$ 282, del Consejo Consultivo de Cataluña relativo al Proyecto de Ley del derecho a la vivienda de Cataluña (2007), no cuestiona que la ley catalana respeta el contenido esencial del derecho de propiedad ni advierte vulneración alguna del principio de proporcionalidad, con base en el propio artículo 47 de la Constitución que impone una obligación a los poderes públicos para hacer efectivo el derecho a la vivienda.

En definitiva, y sin extenderme más en la doctrina constitucional ya consolidada sobre el contenido esencial del derecho de propiedad (STC 37/1987, de 26 de marzo, FJ. 2, 4 y 5), considero conforme a la Constitución que el legislador autonómico imponga al propietario, persona física o jurídica, el deber de ocupar las viviviendas. Todo ello, evidentemente, sin perjuicio de que el alcance que el legislador haya otorgado a dicho deber de ocupación efectiva sea examinado y, en algún caso, rebatido, a la luz de los principios rectores de la acción administrativa. La imposición de un deber de destinar efectivamente la vivienda a uso habitacional, es decir, obligar a los 
propietarios de viviendas a que las mantengan ocupadas, es un límite inherente a la función social de la propiedad que no transforma el contenido esencial de tal derecho y que, como tal, no resulta indemnizable.

(c) La Ley catalana 14/2015, de 21 de julio y la ley vasca 3/2015, de vivienda del País Vasco, introdujeron un impuesto o canon sobre viviendas vacías, que también ha sido impugnado ante el Tribunal Constitucional y cuya vigencia ha sido suspendida. ${ }^{10}$ Esta nueva figura impositiva se articula como un impuesto directo cuyo objeto de gravamen es el incumplimiento de la función social de la propiedad de las viviendas por el hecho de permanecer desocupadas de forma permanente, y ha sido calificada como "despropósito de la proliferación normativa en general" (Menéndez MoreNO, 2015). Los dictámenes del consejo de Estado elaborados con ocasión del recurso de inconstitucionalidad interpuesto contra estas leyes insisten en que tales medidas suponen "una privación desproporcionada del derecho de uso, que debe entenderse contraria al contenido esencial del derecho de propiedad reconocido en el artículo 33 de la Constitución y que vulnera las condiciones básicas del ejercicio de este derecho". ${ }^{11}$ A juicio de URBANO (2016), el gravamen sobre vivienda desocupada en sus distintas manifestaciones respeta el principio de capacidad económica, aunque plantea problemas competenciales y también de doble imposición. Habrá que esperar, en definitiva, al futuro pronunciamiento del Tribunal Constitucional.

\section{2. ¡Exprópiense!}

Las leyes de vivienda autonómicas regulan supuestos expropiatorios muy diferentes y de gran repercusión mediática. En realidad, no todos ellos implican una privación coactiva del derecho de propiedad, sino tan sólo de ciertas facultades como el uso o el usufructo, que son derechos reales sobre la vivienda, y únicamente de forma temporal. La expropiación forzosa penaliza la existencia de viviendas deshabitadas o resuelven problemas urgentes de exclusión social, propios de una coyuntura económica en crisis.

(a) El primer supuesto que se regula es la llamada expropiación forzosa por incumplimiento de la función social de la propiedad. Esta conocida como "expropiación-san-

10 El nuevo impuesto de la Ley catalana 14/2015 grava el incumplimiento de la función social de la propiedad de las viviendas por el hecho de permanecer desocupadas de forma permanente. La Ley se ampara en la potestad tributaria y la competencia exclusiva en materia de vivienda de los artículos 137 y 202 del Estatuto de autonomía de Cataluña. Por lo que se refiere a la Ley vasca de vivienda (Ley 3/2015, de 18 junio), introduce un canon sobre vivienda deshabitada, de carácter extrafiscal, que permite a los Ayuntamientos gravar las viviendas declaradas deshabitadas y cuyos ingresos quedan afectos al patrimonio público del suelo (art. 57).

11 Dictamen del consejo de Estado 108/2016, de 17 de marzo 2016, relativo a la Ley 3/2015, de vivienda del País vasco, y 146/2016, de 14 de abril de 2016, con ocasión de la Ley catalana 14/2015. 
ción" no es nueva en nuestro ordenamiento jurídico: la ley de expropiación forzosa de 1954 ya regula una modalidad de expropiación "por causa de interés social" (artículos 71 a 75 de la LEF).

Las leyes de vivienda autonómicas "de nueva generación”, al imponer un deber jurídico de ocupación efectiva a cualquier propietario de vivienda, no sólo de viviendas protegidas, han dado un paso adelante ampliando los supuestos expropiatorios por incumplimiento de la función social de la propiedad. Encontramos ejemplos de esta expropiación-sanción de viviendas vacías en las leyes de vivienda de Navarra ${ }^{12}$, País $\operatorname{Vasco}^{13}$ y Cataluña ${ }^{14}$, con distinto alcance y contenido. Esta modalidad expropiatoria ha sido objeto de diversos recursos de inconstitucionalidad promovidos por el Gobierno, al considerar que vulnera la competencia exclusiva del Estado de los números $1^{\circ}$ y $8^{\circ}$ del artículo 149.1 de la Constitución y que supone un trato discriminatorio injustificado para las personas jurídicas. Desde un análisis económico del Derecho, se podría plantear si resultan más efectivos otros métodos no expropiatorios de penalización de la vivienda vacía, de carácter fiscal o sancionador, como los que encontramos casi todos los países del entorno europeo y han empezado a introducir las leyes autonómicas. Pero, dándose los presupuestos legales y respetando el procedimiento expropiatorio de la LEF, la expropiación del uso de una vivienda vacía para darle

12 La Ley foral navarra de vivienda (Ley 10/2010, tras la reforma operada por ley foral 24/2013, de 2 de julio) establece que será causa justificativa de expropiación forzosa por incumplimiento de la función social de la propiedad "mantener una vivienda deshabitada en los casos en que constituye infracción sancionable" y "no haber cumplido en el plazo concedido al efecto el requerimiento para poner fin a tal situación" (artículos 42 bis a 42 septies y 52.2.a). La causa expropiandi consiste en tener una vivienda vacía sin causa justificada y haber incumplido el requerimiento correspondiente. Estamos ante un caso de expropiación plena de la propiedad que sólo se pone en marcha cuando el propietario de la vivienda deshabitada es una persona jurídica (ex. artículo 66.1). La ley navarra reconoce que "la persona expropiada tendrá derecho a una indemnización consistente en el valor de la vivienda y anejos vinculados" (artículo 54.1) y que la vivienda expropiada será de nuevo adjudicada "atendiendo a las necesidades generadas en la ejecución de las políticas de vivienda" (disposición adicional segunda) o con destino a la bolsa de alquiler o parque público de viviendas para personas con dificultades de acceso a una vivienda (artículo 42septies.1.a). Esta regulación de la vivienda deshabitada está pendiente de recurso ante el Tribunal Constitucional y se encuentra suspendida.

13 La Ley 3/2015, de 18 de junio, de vivienda del País Vasco introduce un supuesto de expropiación forzosa de vivienda por incumplimiento de su función social (art. 75), pero este precepto ha sido impugnado también ante el Tribunal Constitucional y se encuentra suspendido.

14 La Ley catalana de vivienda, Ley 18/2007, regula la expropiación forzosa de la propiedad por incumplimiento de los deberes de conservación y rehabilitación, bajo una doble condición: que se hayan agotado las vías de fomento y coercitivas previas y que exista un riesgo para la seguridad de las personas (artículo 40). Nótese que este procedimiento expropiatorio se limita hoy a los supuestos de incumplimiento de los deberes de conservación y rehabilitación, ya que tras la reforma operada por Ley 9/2011, el incumplimiento del deber de habitación sólo acarrea la imposición de sanciones. La Ley catalana 24/2015, de 9 de julio, ha introducido una cesión obligatoria de viviendas por un período de tres años para las viviendas vacías que sean propiedad de personas jurídicas (art. 7), precepto que ha sido impugnado ante el Tribunal Constitucional. 
ocupación efectiva no me parece contraria a los principios constitucionales ni tampoco aprecio vulneración de la competencia estatal. Esta interpretación, como es sabido, no es la que ha adoptado el Tribunal constitucional en su conocida sentencia de 14 de mayo de 2015.

(b) Incluyo en este epígrafe la posibilidad de acordar el alquiler forzoso de viviendas declaradas deshabitadas o en situación de sobreocupación, prevista en la legislación catalana ${ }^{15} \mathrm{y}_{\text {vasca }}{ }^{16}$. A diferencia del supuesto anterior, estamos ante una expropiación no plena porque sólo afecta al usufructo de la vivienda, dejando incólume el derecho de nuda propiedad, tanto de personas físicas como jurídicas. Es decir, afecta sólo "a facultades parciales del dominio o de derechos o intereses legítimos" como se define en la legislación de expropiación forzosa.

(c) En tercer lugar, las leyes autonómicas de Andalucía ${ }^{17}$, Navarra $^{18}$, Canarias $^{19}$, País Vasco ${ }^{20}$ y Valencia ${ }^{21}$ introducen una nueva causa expropiandi por circunstancias de emergencia social derivadas de un desahucio en procedimientos de ejecución hipotecaria. Este supuesto se caracteriza por ser una expropiación no plena, de carácter urgente, que afecta sólo al uso de la vivienda y no a la nuda propiedad, además de ser temporal y estar condicionada por situaciones de emergencia o exclusión social (con más detalle, Moreu Carbonell, 2014: 396). Todas ellas han sido impugnadas por el

$15 \quad \mathrm{Al}$ supuesto de sobreocupación ya previsto en la Ley catalana de vivienda 18/2007 (art. 43.3), se une la cesión obligatoria por un período de tres años en el caso de viviendas vacías, introducido por la Ley 24/2015 (art. 7), suspendido e impugnado ante el Tribunal Constitucional.

16 La ley 3/2015, de 18 de junio, de vivienda del País vasco regula el alquiler forzoso de vivienda deshabitada (art. 59), también impugnado ante el Tribunal Constitucional.

17 La polémica reforma fue realizada mediante Decreto-Ley 6/2013, de 9 de abril, de medidas para asegurar el cumplimiento de la función social (disposición final segunda), luego aprobado como Ley 4/2013, de 1 de octubre.

18 La Ley Foral 10/2010, de 10 de mayo, del derecho a la vivienda de Navarra, fue reformada por la Ley Foral 24/2013, de 2 de julio, de medidas urgentes para garantizar el derecho a la vivienda, que incluye esta nueva causa expropiandi para viviendas objeto de desahucios por circunstancias de emergencia social (disposición adicional décima).

19 La Ley 2/2014, de 20 de junio, ha reformado la Ley 2/2003, de 30 de enero, de vivienda de Canarias para introducir la expropiación temporal del uso de viviendas con un procedimiento casi idéntico al de las leyes andaluza y navarra (disposición adicional cuarta).

20 La Ley 3/2015, de 18 de junio, de vivienda del País Vasco introduce también este supuesto de expropiación temporal y declaración de interés social y urgencia de la necesidad de vivienda para personas en especiales circunstancias de emergencia social incursas en procedimientos de desahucio por ejecución hipotecaria (arts. 9.4. y 74 y 75 ).

${ }_{21} \quad$ La Ley 2/2017, de 3 febrero, de función social de la vivienda de la Comunidad Valenciana, regula idéntica declaración del interés social y la necesidad de ocupación a efectos de expropiación forzosa del usufructo temporal de viviendas incursas en procedimiento de desahucio por ejecución hipotecaria para la cobertura de necesidad de vivienda de personas en especiales circunstancias de emergencia social (art. 13). La Comisión Bilateral de Cooperación Administración General del Estado-Generalitat ha acordado iniciar negociaciones para evitar el conficto ante el Tribunal Constitucional. 
Gobierno ante el Tribunal constitucional y su vigencia se encuentra temporalmente suspendida.

La sentencia del Tribunal constitucional 93/2015, de 14 de mayo, es la única dictada hasta la fecha en relación con estos supuestos expropiatorios de emergencia social, en sentido estimatorio del recurso, si bien con votos particulares discrepantes de cuatro magistrados del Tribunal Constitucional. Toda la argumentación contra esta expropiación de viviendas en circunstancias de emergencia social se basa en la invasión de la competencia estatal ex artículo $149.1 .13^{\circ}$ de la Constitución, una competencia transversal que permite al Estado regular "las bases y coordinación de la planificación general de la actividad económica", y que ha conducido a una extensión desmesurada de la competencia estatal, como expondré luego. El nuevo supuesto expropiatorio había sido criticado también por otras razones, que exponen CARRASCO Perera y Lozano Cutanda (2013: 6), quienes consideran difícilmente justificable ante los contribuyentes andaluces que la Administración tenga que pagar para la adquisición de un usufructo temporal, cuando podía perfectamente arrendar viviendas sociales o protegidas de su titularidad o cuya titularidad pueda adquirir mediante la promoción pública o privada de vivienda protegida.

\section{3. ¡Esto nos pasa por vivir por encima de nuestras posibilidades!}

Otra de las razones que explicaría el elevado número de ejecuciones hipotecarias por impago de la hipoteca es el excesivo endeudamiento familiar en relación con la vivienda habitual. ${ }^{22}$ Por eso, las últimas leyes de vivienda autonómicas incluyen medidas variopintas que pretenden paliar o evitar el sobreendeudamiento familiar, mediante la regulación de un procedimiento extrajudicial y, en su caso, de un procedimiento judicial, como la Ley catalana 24/2015, de 29 de julio, de medidas urgentes para afrontar la emergencia en el ámbito de la vivienda y la pobreza energética, que es fruto, por cierto, de una iniciativa legislativa popular impulsada por la Plataforma de Afectados por la Hipoteca $(\mathrm{PAH})$.

\section{OBSTÁGULOS DE ESTA GASGADA NORMATIVA EN MATERIA DE VIVIENDA}

Todas estas reformas legislativas, este activismo normativo en el ámbito de la vivienda, no está siendo fácil de llevar a la práctica. No sólo porque algunos de los

22 Según un estudio difundido por ADICAE (2012): El comportamiento del consumidor financiero, sus nuevos hábitos y costumbres ante la reestructuración del sector bancario, realizado en diciembre de 2012, el gasto por hipoteca supone más del $40 \%$ de los ingresos familiares para casi un $37 \%$ de la muestra encuestada (en www.cambialabanca.es/estudios, recuperado: mayo 2016). Véase el análisis de Bengoetxea Caballero (2014) en relación con el informe del Consejo Económico y Social Vasco (2014). 
derechos recogidos ahora en las normas son imposibles de aplicar si no se crea una infraestructura adecuada para ello, sino también porque gran parte de las normas se encuentran paralizadas por el Tribunal Constitucional, a la espera de un pronunciamiento que quizás sea desfavorable.

1. Se está avanzando a pasos de gigante, pero sigue siendo insuficiente la protección jurisdiccional del derecho a la vivienda

El derecho del artículo 47 de la Constitución no es susceptible de recurso de amparo ni goza de la garantía de los derechos fundamentales, pero está claro que impone al legislador y a los poderes públicos la adopción de las medidas necesarias para conseguir el acceso de todos los ciudadanos a una vivienda digna y adecuada. ${ }^{23}$ El Tribunal Constitucional, en su sentencia 93/2015, de 14 de mayo, relativa al Decreto-Ley de vivienda de Andalucía, acude precisamente al argumento de que el derecho a la vivienda "más que un derecho subjetivo es un mandato a los poderes públicos autonómicos", para negar que se exceda de los límites materiales del Decreto-Ley, ya que no afecta al derecho de propiedad del artículo 33 de la Constitución (FJ.14).

No obstante, el propio Tribunal Constitucional ha admitido el recurso de amparo frente a ciertos derechos sociales vinculándolos con derechos fundamentales, abriendo así una vía indirecta para su protección. El reconocimiento de derechos sociales a través de la conexión con derechos fundamentales supone la progresiva superación de la doctrina clásica, más rígida, y en cierto modo, una modalidad de activismo judicial que asume la necesidad de hacer efectivos ciertos derechos de contenido social como la vivienda o el medio ambiente. ${ }^{24}$

Pero, ¿qué puede hacer un ciudadano que no tiene acceso a una vivienda "digna y adecuada" o que se ve privado de ella? Este es el quid de la cuestión, porque la distancia que media entre el reconocimiento legal del derecho y su alegación ante la jurisdicción ordinaria es un abismo difícil de sortear. El desarrollo legal ha sido tan parco y moderado, que la exigibilidad judicial del derecho a la vivienda es hoy una tarea hercúlea. En expresión de Pisarello (2009, 5), sigue siendo un derecho subjetivo "en (de)construcción" porque la acción para defenderla ante los tribunales es claramente insegura e insuficiente (también GonzÁlez Ordovás, (2013, 79) y GA-

${ }_{23}$ La doctrina española se esfuerza por reconocer que estamos ante un auténtico derecho subjetivo y no ante un simple principio rector. Uno de los más fervientes defensores de esta tesis que defiende la existencia de un "derecho fundamental social" a la vivienda es Escobar Roca y González González (2012), inspirándose en las conocidas tesis sobre los derechos fundamentales de R. ALEXy (1993, traducción española). Al respecto también, López RAMón (2014).

${ }_{24}$ Por ejemplo, en su conocida STC 119/2001, de 24 de mayo, en la que considera la contaminación acústica como un ataque al derecho fundamental a la inviolabilidad del domicilio (FJ. 6). Sobre este planteamiento, véase Díaz Crego (2012: 20) y Cubero Marcos (2017: 125). 
RRIDO GutiéRrez (2012, 3 y 2015, 399). En nuestro país, el derecho a la vivienda existe en términos formales, pero las leyes que lo regulan suelen ser simples normas de medios para atender a la demanda de vivienda, especialmente de protección pública, no articulan los instrumentos necesarios para garantizar el derecho subjetivo a la vivienda; es decir, no establecen obligaciones de resultado (BAssols Coma, 2011, 15 y Alli Aranguren, 2011, 97).

Apunta López RAmón $(2014,58)$ que es sorprendente que el legislador se dedique a atribuir derechos carentes de efectividad y que el desarrollo legal del derecho a la vivienda no ha sido capaz de definir elementos tan esenciales como los relativos a los sujetos titulares del derecho, las personas obligadas a prestarlo y sus contenidos precisos. La vivienda de protección oficial, junto con el planeamiento urbanístico y las subvenciones públicas, han sido las técnicas dominantes de las políticas de vivienda en España, que apenas han variado en los últimos cincuenta o sesenta años (Tejedor Bielsa, 2012, 50). Por eso, ha llegado el momento de fijar medidas concretas para dotar de efectividad el derecho a la vivienda, consolidándolo como derecho jurídicamente exigible tanto ante la Administración como ante los tribunales y los agentes económicos (Roca Caldera, 2010, 235).

Las comunidades autonómas están dando pasos -zsen unos casos tímidos y en otros más valientes- hacia la justiciabilidad del derecho efectivo a la vivienda, es decir, su alegación efectiva ante juzgados y tribunales. La Ley 18/2007, de vivienda de Cataluña declara la acción pública para exigir en vía administrativa y jurisdiccional el cumplimiento efectivo del derecho a la vivienda (art. 6). La Ley 10/2016, de 1 de diciembre, de medidas de emergencia en relación con el acceso a la vivienda en la comunidad autónoma de Aragón, incluye la garantía del derecho a una alternativa habitacional digna (art. 19). La Ley 2/2017, de 3 de febrero, de función social de la vivienda de la Comunidad valenciana, reconoce que el derecho a una vivienda asequible, digna y adecuada "genera la obligación jurídica de la administración autonómica valenciana y de las administraciones locales radicadas en la comunidad valenciana de poner a disposición del solicitante la ocupación estable de un alojamiento dotacinoal, de una vivienda protegida o de una vivienda libre" (art. 2.3). En opinión de Ponce Solé (2008b, 218), el reconocimiento de esta acción pública es altamente positiva y frente a los recelos de un sector doctrinal escéptico, tiene más ventajas que inconvenientes porque refuerza el derecho a la ciudad y a la vivienda. Siguiendo la estela de la legislación catalana, la Ley 3/2015, de vivienda del País Vasco, instaura una acción pública en materia de vivienda (art. 6.1) y no sólo eso, sino que también abre el recurso a la vía jurisdiccional precisa para hacerlo efectivo allí donde sea incumplido por los poderes públicos (art. 6.2) 25. MoLTó,

25 Este "derecho subjetivo a la vivienda" se reconoce a quienes tengan derecho a acceder a la ocupación de una vivienda o alojamiento protegido, y podrán reclamar su cumplimiento ante el departamento com- 
Josep M. y Ponce, Juli (2016: 1) se atreven a señalar que se ha desfondado el mito de que la vivienda es un simple principio rector y no un auténtico derecho subjetivo, porque ahora ya existen medios jurídicos eficaces para hacerlo efectivo. ${ }^{26}$

Estas medidas se están encontrando con el obstáculo importante del recurso ante el Tribunal Constitucional, ya que están siendo objeto de recursos de inconstitucionalidad interpuestos por el Gobierno y, por ende, su vigencia ha quedado suspendida. Creo que es un poco aventurado afirmar que, al menos en España, existen medios efectivos para exigir el derecho subjetivo a la vivienda. Así que por más que forcemos la letra de la ley para concluir que sí, que existe un derecho subjetivo a la vivienda, no encontramos el medio de hacerlo efectivo ante los tribunales, a pesar de la amplísima legitimación subjetiva que reconocen hoy las leyes procesales. Una logomaquia más de nuestro ordenamiento jurídico, en la que atendemos más a las palabras que al fondo real del asunto.

Pero las palabras vacías ya no son suficientes para el Tribunal de Justicia de la Unión Europea, que ha dejado meridianamente claro que la vivienda es un derecho fundamental garantizado por el artículo 7 de la Carta de los Derechos Fundamentales de la Unión Europea ("toda persona tiene derecho al respeto de su vida privada y familiar, de su domicilio y de sus comunicaciones"), que los Estados miembros deben regular sistemas efectivos de defensa y que los jueces nacionales pueden ordenar las medidas necesarias (cautelares, provisionales) para garantizar la efectividad de tal derecho (por todas, STJUE de 14 marzo 2013, caso Aziz, ECLI:EU:C:2013:164, apdo. 59 y 10 septiembre 2004, caso Kusionová, ECLI:EU:C:2014:2189, apdo. 67). Estos pronunciamientos del TJUE constituyen un decisivo avance en el proceso de construcción del derecho subjetivo a la vivienda y fundamentan una actitud proactiva de los tribunales.

petente en materia de vivienda del gobierno vasco, cuyas resoluciones serán recurribles ante la jurisdicción contencioso-administrativa.

26 Las nuevas leyes españolas se inspiran, indudablmenten, en la Ley francesa 2007-290, de 5 de marzo, que regula el "droit au logement oposable" (DALO), algo así como el derecho de alojamiento exigible o reclamable. Al respecto, INSERgUet-Brisset $(2010,36)$ y sobre la situación del derecho a la vivienda en Europa, KenNa (2009). La Ley DALO impone al Estado la obligación de facilitar alojamiento a toda persona con residencia regular en territorio francés que no pueda acceder por sus propios medios a un alojamiento digno y autosuficiente. Se configura como un recurso especial abierto a quienes se encuentran en alguna de las situaciones reguladas por la Ley y que, resumidamente, vienen a identificarse con la falta de vivienda: no tener domicilio fijo; estar amenazado de expulsión sin posibilidad de realojo; residir en viviendas insalubres o peligrosas, especialmente con menores o discapacitados a su cargo; o ser demandante de una vivienda social durante un tiempo anormalmente largo y no haber recibido respuesta de la Administración. La sentencia del TEDH 9 de abril de 2015, Tchokontio Happi c. Francia, condenó al Estado francés por no haber realojado a una familia camerunesa en situación de emergencia social, así que está claro que es un derecho. 
Habrá que ir adoptando estas medidas eficaces si no queremos que los organismos internacionales nos saquen los colores, como ha ocurrido con el Comité de Derechos Económicos, Sociales y Culturales de las Naciones Unidas (CESCR), que es el órgano de la ONU encargado de proteger el Pacto Internacional de Derechos Económicos, Sociales y Culturales (PIDESC). El CESCR ha condenado a España ya en dos ocasiones por violar el derecho a la vivienda de una mujer cuya vivienda habitual había sido objeto de un procedimiento de ejecución hipotecaria (comunicación núm. 2/2014, publicada en E/C.12/55/D/2/2014, de 13 octubre 2015) y de una familia con dos hijos menores de edad que había sido desahuciada y acabó durmiendo en un coche (comunicación núm. 5/2015, publicada en E/C.12/61/D/5/2015, de 20 junio 2017). La ONU insta a España a adoptar las medidas legislativas necesarias que garanticen la observancia de los derechos reconocidos en el citado pacto internacional, en concreto los artículos 11.1 y 2.1, antes de que se produzca cualquier desalojo de vivienda, se asegure la accesibilidad a recursos jurídicos a quienes se enfrentan a procedimientos de ejecución hipotecaria y se suministren alternativas habitacionales en estos casos. Son las primeras comunicaciones adoptadas en el seno de la ONU en casos individuales presentados en aplicación del Protocolo Facultativo que entró en vigor para España el 5 de mayo de 2013. ¿Serán las últimas?

\section{El confuso diseño competencial y el reforzamiento del poder central vía extensión competencial}

Y, en fin, aunque se ha discutido mucho en la doctrina sobre la exigibilidad del derecho a la vivienda ante los tribunales, y sobre si la vivienda es o no un derecho subjetivo, creo que es imprescindible replantear si la garantía judicial, por su lentitud y coste, es una medida adecuada para conseguir la efectividad del derecho a la vivienda. Obsesionarnos con este reconocimiento nos puede llevar a infrautilizar otras vías de resolución de conflictos menos rígidas y más eficaces, al menos en el ámbito de la vivienda, más cercanas al ombudsman o defensor del ciudadano, como el "defensor local” que actúa en el Reino Unido con plena independencia financiera de la clase política.

La convivencia entre las normas estatales y las autonómicas, entre las políticas adoptadas por unos y otros gobiernos, no está siendo pacífica. La crisis económica y financiera ha generado en España un aluvión de medidas, muchas de ellas aprobadas mediante leyes de emergencia (Decretos-Leyes), que no sólo han reforzado las competencias del Estado (central), sino que han conducido también a un peligroso círculo de recentralización competencial y restricción de competencias autonómicas, como se ve muy bien en el conflicto relativo a la expropiación forzosa de viviendas por razón de emergencia social (STC 93/2015, de 14 de mayo, con votos particulares de cuatro magistrados). 
La STC 93/2015, considera que las medidas introducidas por el legislador andaluz vulneran la competencia estatal en materia de bases y coordinación de la actividad económica del artículo 149.1.13 de la Constitución, haciendo notar la repercusión que podría tener sobre el mercado de crédito e hipotecario, al afectar directamente a uno de los elementos esenciales de la hipoteca, cual es la ejecutividad de la garantía real y la libre disposición del bien hipotecado por el acreedor hipotecario. Según el Tribunal Constitucional, el supuesto expropiatorio regulado en la ley andaluza (el argumento resulta extensible a las leyes navarra, canaria y vasca) obstaculiza y hace incompatibles las medidas adoptadas por el Estado en materia de política económica. Entre otras, la suspensión del plazo de varios años del lanzamiento cuando en un proceso de ejecución hipotecaria se adjudique al acreedor la vivienda habitual de una persona, prevista en la Ley 1/2013, de 14 de mayo, de medidas para reforzar la protección a los deudores hipotecarios, reestructuración de la deuda y alquiler so$\mathrm{cial}^{27}$. Sorprende que el Tribunal Constitucional considere que, una vez ejercitada la competencia estatal de regulación de las bases o planificación de un sector económico, en este caso la vivienda, la comunidad autónoma quede privada, mermada y condicionada para desarrollar sus propias competencias (las de vivienda). El desarrollo por el Estado del artículo 149.1.13 ${ }^{\mathrm{a}}$ produce, a juicio del Tribunal constitucional, un efecto de bloqueo de la competencia sectorial autonómica, como se encarga de denunciar el voto particular del magistrado J.A. Xiol Ríos, que comparto plenamente.

En mi opinión, la normativa autonómica no interfiere en la regulación estatal: simplemente la deja aplazada hasta que transcurra el plazo de suspensión. Y, desde luego, la eventual interferencia de medidas de política económica dictadas por el Estado y la comunidad autónoma ante un mismo problema (la protección de determinados colectivos vulnerables en materia de vivienda) no debería conducir a la inconstitucionalidad de la norma autonómica, en el sentido expuesto por el voto particular de la magistrada Adela Asua Batarrita, que también comparto.

En definitiva, el Tribunal Constitucional da por bueno que el Estado, en virtud del título competencial del artículo $149.1 .13^{\circ}$ de la Constitución, pueda imponer de modo excluyente la solución a un problema social y económico como es el de la vivienda, cerrando el paso a que las comunidades autónomas puedan desarrollar sus propias políticas. Esto supone, como afirma el voto particular de la magistrada Adela Asua Batarrita, un constreñimiento excesivo de competencias autonómicas y una grave erosión y distorsión del sistema competencial. Causa perplejidad que

27 La STC 213/2016, de 15 de diciembre, ha desestimado el recurso de inconstitucionalidad interpuesto por el Grupo Parlamentario Socialista del Congreso de los Diputados por ciertas irregularidades cometidas durante su tramitación parlamentaria y contra el contenido de algunos preceptos concretos de la ley. 
el Tribunal Constitucional afirme que una vez ejercida la competencia estatal, las Comunidades Autónomas no pueden ejercer ya las suyas sobre el sector de la vivienda, aun cuando no exista real menoscabo de la competencia estatal. Aquí coincide el voto particular que formula la magistrada doña Encarnación Roca Trías, al que se adhiere don Fernando Valdes Dal-Ré, cuando advierten que en modo alguno la competencia ex art. $149.1 .13^{\circ}$ puede servir para atribuir al Estado una competencia exclusiva para regular de modo uniforme la materia de vivienda, excluyendo cualquier posibilidad de regulación por parte de las Comunidades Autónomas. La crisis económica ha servido de excusa, una vez más, para un proceso de recentralización.

\section{Fragmentación excesiva de las políticas de vivienda}

A juicio de Pamparacuatro Martín (2015, 185), la tremenda dispersión de las fuentes de producción legislativa es una de las causas que explicaría la crisis del Derecho. En el ámbito de la vivienda esta afirmación cobra sentido, al menos en lo que afecta a la calidad normativa y a la coherencia de las medidas adoptadas. Uno de los problemas estructurales del urbanismo español, extensible a las políticas de vivienda, es la fragmentación normativa, y además la improvisación de tratamientos jurídicos distintos, la velocidad con la que se ofrecen respuestas jurídicas, ponen en peligro los principios de igualdad y de seguridad jurídica (Moreu Carbonell, 2014: 377). La imaginación de los legisladores autonómicos incluye medidas muy diversas, algunas alejadas de la inmediata satisfacción del derecho constitucional a la vivienda, lo cual, unido a la tozudez y al inmovilismo del gobierno estatal, explican los conflictos actuales. Desde que el Presidente del Gobierno las impugnó ante el Tribunal Constitucional, la vigencia de las leyes andaluza, navarra, canaria, catalana y vasca ha quedado suspendida y, a tenor del fallo estimatorio del recurso de inconstitucionalidad interpuesto contra la ley andaluza (el único resuelto hasta la fecha), cabe intuir que todas acabarán por ser declaradas inconstitucionales.

\section{EN CONCLUSIÓN}

A la vista de lo analizado hasta aquí, podemos concluir que las reformas en materia de vivienda desarrolladas en los últimos cinco o seis años se deben, en gran medida, a la presión del activismo social y a una clase política que, más o menos concienciada, pero casi siempre con un sesgo oportunista, sin olvidar el contexto económico, está recogiendo las demandas de los ciudadanos. Lo cierto es que, siendo puristas, la calidad de las normas no ha salido ganando con estas nuevas técnicas, especialmente cuando se recurre a la legislación de emergencia, y que se legisla con más voluntad que acierto. Las comunidades autónomas se encuentran en la tesitura de adoptar medidas plenamente ajustadas al marco constitucional y al entorno europeo, pero también resignadas o conscientes de van a ser recurridas ante el Tribunal 
constitucional. El problema no es que la ciudadanía esté reclamando un papel más activo, no sólo en la producción normativa, y que estén surgiendo nuevos y legítimos modos de acción colectiva alternativos a las (pacatas) fórmulas de participación. No hay que enfocar hacia allí la raíz de todos los males. Supongo que la improvisación es una enfermedad que se cura con el tiempo, una vez que el carácter emergente del activismo social se consolide. En palabras de Conejero Paz y Redondo Lebrero (2016, 20) la innovación social debería tender con el tiempo hacia un formato menos ideologizado y resulta primordial establecer estrategias estables que permitan articularla con éxito.

Esta estabilidad, desde luego, no se consigue con el recurso a la legislación de urgencia ni a medidas de emergencia, tan propia de la época de crisis (durante la $\mathrm{X}$ legislatura 2011-2015 se han batido todos los récords, pues se han aprobado 73 decretos-leyes sobre un total de 143 proyectos de ley). No es casualidad que recientemente se hayan publicado artículos doctrinales con el mismo ilustrativo título de "uso y abuso del Decreto-Ley" (Arana García, 2013 y Aragón Reyes, 2015), para recordarnos que el decreto-ley es una fuente del Derecho de naturaleza y utilización excepcional. Las comunidades autónomas también le han cogido el gustillo a esta técnica (en materia de vivienda, tanto Andalucía como Cataluña), a pesar de las dudas de constitucionalidad que suscita la generalización de esta fuente en el ámbito autonómico (Herráiz Serrano, 2012 y Boix Palop, 2012). Curiosamente, la STC de 14 de mayo de 2015, no discute que el recurso al decreto-ley esté justificado, y afirma que el gobierno andaluz cumplió con la exigencia de presentar explícita y razonadamente la situación extraordinaria, rechazando así los argumentos del Gobierno.

Los obstáculos para que las medidas de intervención en el ámbito de la vivienda tengan éxito ya han sido expuestos, como el confuso reparto competencial y la tendencia centralizadora del Tribunal constitucional. Da la impresión de que se legisla porque está de moda o porque es políticamente correcto, aunque luego no se prevean cauces para hacer efectiva la regulación. Ni la ciencia en general ni la jurídica en particular son ajenas a este fenómeno gregario. Baste pensar en los temas, los conceptos y las teorías que por circunstancias diversas se ponen de moda y que suscitan entre la comunidad científica una atención a todas luces excesiva (Doménech Pascual, 2016, 7). Lamentablemente, en el ámbito de la vivienda encontramos también ejemplos de leyes propaganda (Martín Valdivia, 2015: 4) o leyes-manifiesto, como denuncia ToRnos Mas (2014: 2864), que buscan conseguir un buen titular, pero no terminan de ser eficaces en la consecución de sus objetivos. Las normas sobre vivienda deben ser asequibles, en el sentido de que se deben poder cumplir; no deben elaborarse con una finalidad puramente de marketing o propagandística, sino con la intención de aplicarlas activamente. La clave está, parafraseando a Hamlet ante la calavera, "tener o no tener un derecho subjetivo a la vivienda" (Carrasco Perera, 2011), porque un derecho sin acción y sin medios para hacerlo efectivo no es un derecho subjetivo. 
Los problemas estructurales de la vivienda en España no se resuelven con parches legislativos a golpe de activismo e impulso social, que tienen un limitado impacto económico y, desde luego, prácticamente nulo para la estabilidad bancaria, ni para el proceso de reestructuración establecido por la Unión europea, a pesar del revuelo generado y de una atención mediática desmesurada. En mi opinión, las novedades introducidas apresuradamente y en medio de fuertes presiones sociales por las leyes autonómicas en materia de vivienda -y no digamos las del Estado, que son inapreciables-, dan pequeños pasos en la protección del derecho a la vivienda, pero no tienen carácter estructural. Existe el riesgo de que todas estas reformas queden en papel mojado y no sirvan para que se articule un derecho efectivo a la vivienda (demasiados cambios para que todo siga igual). Me da la impresión de que esta forma de legislar fragmentada y basada en grandes declaraciones formales está legitimando la inacción y la disolución de las concretas obligaciones jurídicas asociadas a derechos, tras el velo de una jerga político-burocrática que no sería más que humo sofisticado que encubriría la falta de diligencia de la clase política (son palabras de PONCE Solé, 2014: 7). Por último, son medidas que sólo han tenido en cuenta los intereses de una clase media con poder adquisitivo, que ha podido acceder a una vivienda en el mercado inmobiliario (deudores hipotecarios, propietarios), pero que dejan de lado a quienes ni siquiera tienen acceso a una vivienda digna (marginados, sin techo) y a los que no son propietarios de vivienda (piénsese en la regulación del "desahucio exprés" que refuerza la posición del arrendador, sin que se prevean medidas de apoyo al inquilino por razones de vulnerabilidad social). Los olvidados, salvo excepciones, son los de siempre. 


\section{BIBLIOGRAFÍA}

Alexy, Robert (1993): Teoría de los derechos fundamentales, CEG, Madrid.

Alli Aranguren, Juan Cruz (2011) "El irreconocible derecho a la vivienda en la Ley formal 10/2010, de 10 de mayo”, Revista de Derecho Urbanístico y Medio Ambiente, no 268, 2011, pgs. 69 a 121.

Alonso García, Ma Teresa, dir. (2014) Vivienda y crisis económica. Estudio jurídico de las medidas propuestas para solucionar los problemas de vivienda provocados por la crisis económica, Pamplona, Aranzadi.

Amnistía Internacional (2015). Derechos desalojados. El derecho a la vivienda y los desalojos hipotecarios en España (Informe), Madrid, en https://grupos.es.amnesty.org/ uploads/media/informe_vivienda_jun_15_Derechos_desalojados.pdf.

Aragón Reyes, Manuel (2015): "Uso y abuso del Decreto-Ley: una propuesta de reinterpretación constitucional”, El Cronista del Estado Social y Democrático de Derecho N. 60, pp. 12 a 17.

Arana García, Estanislao (2013): "Uso y abuso del Decreto-Ley", RAP n 191, pp. 337 a 365.

Atienza, Manuel (2013a): Podemos hacer más. Otra forma de pensar el Derecho, Pasos Perdidos.

Atienza, Manuel (2013b): "Los desahucios, los jueces y la idea del derecho", El Cronista del Estado Social y Democrático de Derecho n. 37, pp. 14 a 19.

Bassols Coma, Martín (2011). "El derecho a la vivienda ante la crisis económica y el cambio climático: intervención de las Administraciones públicas ante situaciones de vulnerabilidad social y urbanística", Revista General de Legislación y Jurisprudencia, pgs. $13-42$.

Bengoetxea Caballero, Joxerramon (2014): "Sobre-endeudamiento, desahucio, abuso del derecho y cultura judicial formalista", El Cronista del Estado Socialy Democrático de Derecho no 48, pp. 50 a 55.

Boix PAlop, Andrés (2012): "La inconstitucionalidad del Decreto-ley autonómico", Asamblea. Revista parlamentaria de la Asamblea de Madrid no 27, pp. 121 a 148.

Carrasco Perera, Ángel (2011). "Tener y no tener un derecho subjetivo a la vivienda”, Actualidad Furídica Aranzadi no 814. 
Garrasco Perera, Ángel y Lozano Gutanda, Blanca (2013). "Decreto Ley 7/2013, de 9 de abril, para asegurar el cumplimiento de la función social de la vivienda en Andalucía: una nota de urgencia", Centro de Estudios de Consumo, pp. 1 a 6, http://blog.uclm.es/cesco/files/2013/04/Decreto-Ley-andaluz-vivienda-RV.pdf.

Carrillo, Marc (2015): "La libertad de expresión de los jueces”, El Cronista del Estado socialy democrático de Derecho n. 53-54, pp. 16 a 27.

Cesteros, Luis (2012). "Los problemas estructurales del urbanismo español y la necesidad de un cambio de modelo", RDUyMA n 275, 2012, pgs. 13 a 23.

Conejero Paz, Enrique y Redondo Lebrero, Juan Garlos (2016): “La innovación social desde el ámbito público: conceptos, experiencias y obstáculos", Gestión y análisis de políticas públicas n $\mathrm{n}^{\circ} 15$, pp. 1 a 20.

Gonsejo Económico y Social Vasco (2014): "El sobreendeudamiento familiar: un análisis desde la CAPV" disponible en www.cesegab.com/Portals/0/Libros/20140327_ El sobreendeudamiento familiar.pdf (recuperado: 24 mayo 2016).

Consejo General del Poder Judicial (2013): "Una aproximación a la conciliación de los datos sobre ejecuciones hipotecarias y desahucios", Boletín de Información Estadística $\mathrm{n}^{\mathrm{o}} 35$, pp. 1 a 9.

Gubero Marcos, José Ignacio (2017), "El reconocimiento de derechos sociales a través de la conexión con derechos fundamentales: hacia una progresiva superación de la doctrina clásica”, Revista Catalana de Dret Públic, núm. 54 pp. 118-140.

Defensor del Pueblo (2012): Crisis económica y deudores hipotecarios: actuaciones y propuestas del Defensor del Pueblo, en www.defensordelpueblo.es (recuperado: noviembre 2015).

Díaz Crego, María (2012): "El Tribunal Constitucional y la protección indirecta de los derechos sociales", Lex Social, Revista de los derechos sociales n ${ }^{\circ}$ 1/2102, pp. 5 a 30.

Doménech Pascual, Gabriel (2016): “Que innoven ellos”, InDret 2/2016, pp. 1 a 41 .

Escobar Roca, Gulllermo y González González, Beatriz (2012): "El derecho a la vivienda", ob. col. Escobar Roca, Guillermo, Dir: Derechos sociales y tutela antidiscriminatoria, Thomson Aranzadi, Cizur Menor, Pamplona. 
Escudé, Cristina (2017): "La política pública del Ayuntamiento de Terrassa en relación con las viviendas vacías y su desarrollo jurídico", ob. col. Moltó Darner, Josep y Ponce Solé, Juli, coords. Derecho a la vivienda y función social de la propiedad, Aranzadi.

Garcías de España, Eugenia (2013): "Ejecución hipotecaria sobre la vivienda habitual, dación en pago y reclamación posterior", Revista Doctrinal Aranzadi Civil-Mercantil no 10/2013, pp. 1 a 22.

Garrido Gutiérrez, Pilar (2012): "El derecho a una vivienda digna en España. Crisis residencial: origen, consecuencias y respuesta de los poderes públicos", documento disponible en http://www.ararteko.net/.

Garrido Gutiérrez, Pilar (2015): “PPara qué una constitución? Los desahucios a la luz del derecho constitucional a una vivienda digna. Apuntes sobre algunas estrategias defensivas", ob. col. M.A. García Herrera, J. Asensi Sabater, F. Balaguer Callejón (coords.): Constitucionalismo crítico: Liber amicorum Carlos de Cabo Martín, Tirant lo Blanch, Valencia, pp. 399 a 428.

García Inda, Agustín (2015): "Hamburguesas y eficiencia. Del estado del bienestar a la sociedad del bienestar”, Gestión y Análisis de Políticas Públicas no 15, pp. 1 a 13.

González Ordovás, Ma José (2013): El derecho a la vivienda. Reflexiones en un contexto socioeconómico complejo, Dykinson, Universidad de Zaragoza.

Haro Barba, Carmen y Sampedro Blanco, Víctor (2011): "Activismo político en red: del movimiento por la vivienda digna al 15M", Teknokultura. Revista de Cultura Digital y Movimientos sociales, vol. 8, $n^{\circ}$.2, Universidad Complutense de Madrid, pp. 167 a 185, en http://revistas.ucm.es/index.php/TEKN.

Herráiz Serrano, Olga (2012): "Teoría y práctica del decreto-ley autonómico tras su incoporación al sistema de fuentes de algunas comunidades", Corts. Anuario de Derecho Parlamentario n ${ }^{\circ} 25$, pp. 105 a 161.

Inserguet-Brisset, Veronique (2010): "La evolución del Derecho francés en materia de vivienda", ob. col. F. López RAmón (coord.): Construyendo el derecho a la vivienda, Marcial Pons, Madrid, pp. 27 a 64.

Kenna, Padraic (2009): "El derecho a la vivienda en Europa: deberes positivos y derechos exigibles. (Según la jurisprudencia del Tribunal Europeo de Derechos Humanos)", UNED. Revista de Derecho Político n 74, pp. 479 a 501. 
López RAmón, Fernando (2014): "El derecho subjetivo a la vivienda", Revista Española de Derecho Constitucional n ${ }^{\circ}$ 102, págs. 49-91.

Marcellesi, Florent y Martínez Rodríguez, Rosa (2015): “Del activismo social al activismos político: las candidaturas ciudadanas municipalistas en España", Green European Fournal (http://www.greeneuropeanjournal.eu).

Martín Valdivia, Salvador (2013): "El Decreto-Ley andaluz de vivienda 67/2013. ¿Romanticismo, propaganda o función social legítima?", Revista Aranzadi de Urbanismo y Edificación no 28, 2013, pp. 67 a 98.

Martín Valdivia, Salvador (2015). "Derecho de propiedad y política de vivienda: límites constitucionales. Comentario a la STC de 14 de mayo de 2015", $R e^{-}$ vista Aranzadi de Urbanismo y Edificación, no. 34, pp. 1 a 4.

Menéndez Moreno, Alejandro (2015), “Nada es lo que parece. (A propósito del impuesto sobre las viviendas vacías de la Ley de 21 de julio de 2015, de la Generalidad de Cataluña), Revista Quincena Fiscal n ${ }^{\circ} 17$.

Moltó Darner, Josep M. y Ponce, Juli (2016): “L'esfondrament d'un mite: l'habitatge com a dret subjectiu en el marc d'un servei d'interès general i de la funció social de la propietat", blog de la Revista Catalana de Dret Public, RCDP, https://eapc-rcdp.blog.gencat.cat/.

Moltó Darner, Josep M. y Ponce, Juli, coords. (2017): Derecho a la vivienda y función social de la propiedad. Nuevas políticas públicas en el marco del servicio público de alojamiento, Aranzadi.

Montoro Chiner, María Jesús y Sommermann, Karl-Peter, dirs. (2015): Gute Rechtsetzung. La buena legislación, Speyerer Forschungsberichte 281.

Moreu Garbonell, Elisa (2014). "Sanción y expropiación de viviendas deshabitadas por incumplimiento de su función social o en circunstancias de emergencia social”, en Alonso Pérez, Ma Teresa (dir.), Vivienda y crisis económica. Estudio jurídico de las medidas propuestas para solucionar los probelmas de vivienda provocados por la crisis económica, Pamplona, Aranzadi, pp. 369 a 420.

Moreu Garbonell, Elisa (2016), "Activismo social y derecho a la vivienda", ob. col. J. Gifreu Font, M. Bassols Coma y A. Menéndez Rexach, dirs. El derecho a la ciudad y el territorio. Estudios en homenaje a Manuel Ballbé Prunes, INAP, Madrid, pp. 281 a 302. 
Organización Naciones Unidas (2008), Informe del Relator Especial sobre la vivienda adecuada como elemento integrante del derecho a un nivel de vida adecuado, Sr. Miloon Kothari, Adición Misión España, A/HRC/7/16 Add.2.

Pamparacuatro Martín, Javier (2015). "En torno a la crisis del Derecho", Revista de Derecho Político n. 92, pp. 165 a 194.

Pisarello, Gerardo (2009) "El derecho a la vivienda como derecho social: implicaciones constitucionales”, Revista Catalana de Dret Públic no 38, pp. 1 a 13.

Ponce Solé, Juli (1999): "Segregación espacial, derecho urbanístico y jueces audaces en los Estados Unidos de América", Revista Española de Derecho Constitucional n. 57 , pp. 329-354.

Ponce Solé, Juli (2007): "Las políticas públicas dirigidas a facilitar el derecho de acceso a la vivienda: análisis y propuestas, con especial referencia al derecho comparado francés y anglosajón", RVAP n 79.

Ponce Solé, Juli (2008) "La acción pública en materia de vivienda", ob. col. Ponce Solé, Juli y Sibina Tomàs, Domenec (coords.): El derecho de la vivienda en el siglo XXI: sus relaciones con la ordenación del territorio y urbanismo, Marcial Pons, 2008, pgs. 177 a 216.

Ponce Solé, Juli (2014): “Ciencias sociales, Derecho administrativo y buena gestión pública. De la lucha contra las inmunidades del poder a la batalla por un buen gobierno y una buena administración mediante un diálogo fructífero", Gestióny análisis de políticas públicas $n^{\circ} 11$, pp. 1 a 20.

Ponce Solé, Juli (2015) “ ¿Ha expropiado el Tribunal Constitucional las competencias autonómicas en materia de vivienda? A propósito de la STC de 14 de mayo de 2015, declarando la inconstitucionalidad de la regulación andaluza sobre expropiación de viviendas vacías en manos de bancos", blog de l'Institut de Recerca TransJus, http://www.ub.edu/instituttransjus/ (recuperado: 30 noviembre 2015).

Roca Caldera, Josep (2010): "El marco urbanístico de la política de vivienda", ob. col. Leal Maldonado, J. (coord.), La política de vivienda en España, Editorial Pablo Iglesias, Madrid, 2010, pgs. 195 a 236.

Rodríguez Arana, Jaime (2015): Derecho administrativo y derechos sociales fundamentales, INAP, Sevilla. 
Rodríguez Garavito, César, Rodríguez Franco, Diana (2015): Fuicio a la exclusión. El impacto de los tribunales sobre los derechos sociales en el Sur Global, Siglo XXI Editores Argentina.

Schmidt-Assmann, Eberhard (2003): La teoría general del Derecho Administrativo como sistema, edición española, Marcial Pons/Instituto Nacional de Administración Pública, Madrid.

Tejedor Bielsa, Julio C. (2012): Derecho a la vivienda y burbuja inmobiliaria, La Ley, Madrid, 2012, 257 págs.

Tornos MAs, JOAQuín (2014). "El acceso a la vivienda y la nueva función social del derecho de propiedad", Revista Vasca de Administración Pública n especial 99-100, 2014, pp. 2853 a 2871.

Urbano SÁnchez, Lucía (2016), "La tributación de la vivienda vacía en el ámbito autonómico y local. Algunas reflexiones a la luz del artículo 6.3 de la LOFCA", Revista Andaluza de Administración Pública nº 96, págs. 127 a 164.

Vaquer Caballería, Marcos (2014): "Derecho a la vivienda y garantía de un mínimo vital”, El Cronista del Estado Social y Democrático de Derecho N. 48, pp. 34 a 39.

Vaquer Caballería, Marcos (2015): "El derecho a la vivienda en su relación con los derechos a la ciudad y al medio ambiente", Asamblea. Revista parlamentaria de la Asamblea de Madrid n. 32, pp. 121 a 154.

Vaquer Caballería, Marcos, Ponce solé, Juli y Arnaiz Ramos, Rafael (2016): Propuestas jurídicas para facilitar el acceso a la vivienda, Fundación Coloquio Jurídico Europeo, Madrid.

Von Stein, LoRenz (1957): Movimientos sociales y monarquía, versión a cargo de E. Tierno Galván, Instituto de Estudios Políticos, Madrid. 